\title{
Biophsyical constraints on gross primary production by the terrestrial biosphere
}

\author{
H. Wang ${ }^{1}$, I. C. Prentice ${ }^{1,2,3}$, and T. W. Davis ${ }^{2}$ \\ ${ }^{1}$ Department of Biological Sciences, Macquarie University, North Ryde, Australia \\ ${ }^{2}$ AXA Chair Programme in Climate and Biosphere Impacts, Grand Challenges in Ecosystems and the Environment, \\ Department of Life Sciences, Imperial College, Ascot, UK \\ ${ }^{3}$ Grantham Institute for Climate Change, Imperial College, London, UK \\ Correspondence to: H. Wang (han.wang@mq.edu.au)
}

Received: 4 February 2014 - Published in Biogeosciences Discuss.: 25 February 2014

Revised: 28 July 2014 - Accepted: 3 September 2014 - Published: 31 October 2014

\begin{abstract}
Persistent divergences among the predictions of complex carbon-cycle models include differences in the sign as well as the magnitude of the response of global terrestrial primary production to climate change. Such problems with current models indicate an urgent need to reassess the principles underlying the environmental controls of primary production. The global patterns of annual and maximum monthly terrestrial gross primary production (GPP) by $\mathrm{C}_{3}$ plants are explored here using a simple first-principles model based on the light-use efficiency formalism and the Farquhar model for $\mathrm{C}_{3}$ photosynthesis. The model is driven by incident photosynthetically active radiation (PAR) and remotely sensed green-vegetation cover, with additional constraints imposed by low-temperature inhibition and $\mathrm{CO}_{2}$ limitation. The ratio of leaf-internal to ambient $\mathrm{CO}_{2}$ concentration in the model responds to growing-season mean temperature, atmospheric dryness (indexed by the cumulative water deficit, $\Delta E$ ) and elevation, based on an optimality theory. The greatest annual GPP is predicted for tropical moist forests, but the maximum (summer) monthly GPP can be as high, or higher, in boreal or temperate forests. These findings are supported by a new analysis of $\mathrm{CO}_{2}$ flux measurements. The explanation is simply based on the seasonal and latitudinal distribution of PAR combined with the physiology of photosynthesis. By successively imposing biophysical constraints, it is shown that partial vegetation cover - driven primarily by water shortage - represents the largest constraint on global GPP.
\end{abstract}

\section{Introduction}

Differences among model predictions of the terrestrial carbon-balance response to changes in climate and atmospheric carbon dioxide concentration $\left(\left[\mathrm{CO}_{2}\right]\right)$ remain stubbornly large (Ciais et al., 2013; Friedlingstein et al., 2006; Sitch et al., 2008). After reanalysing coupled climatecarbon-cycle model results from Friedlingstein et al. (2006), Denman et al. (2007) revealed disagreements in the overall magnitude of the modelled (positive) climate- $\mathrm{CO}_{2}$ feedback, and also in the responses of key processes - ocean $\mathrm{CO}_{2}$ uptake, soil organic mater decomposition, and especially terrestrial net primary production (NPP) - to $\left[\mathrm{CO}_{2}\right]$ increase and/or climate change. Modelled positive responses of global NPP to $\left[\mathrm{CO}_{2}\right]$ varied by a factor greater than five, while the models disagreed even on the sign of the response of global NPP to climate. The more recent Earth System Models (ESMs) in the Coupled Model Intercomparison Project 5 (CMIP5) archive show no better agreement (Ahlström et al., 2012; Anav et al., 2013; Arora et al., 2013; Friedlingstein et al., 2014; Jones et al., 2013; Todd-Brown et al., 2013). Ciais et al. (2013) summarized the CMIP5 carbon-cycle results (their Fig. 6.21) and highlighted the weak land-carbon uptake response to both $\left[\mathrm{CO}_{2}\right]$ and climate change, shown by two "N-coupled" ESMs (models allowing for interactions between the terrestrial $\mathrm{C}$ and $\mathrm{N}$ cycles). The CMIP5 models collectively show a high bias in the simulation of recent trends in atmospheric $\left[\mathrm{CO}_{2}\right]$, because the modelled uptake of $\mathrm{CO}_{2}$ by the oceans and/or land is too small, being the smallest in the N-coupled models (Hoffman et al., 2013). Several 
"offline" N-coupled land-carbon-cycle models have also generated contradictory and, in some cases, apparently unrealistic responses of NPP to climate (Thomas et al., 2013; Zaehle and Dalmonech, 2011). These disappointing outcomes of recent model development suggest to us that the controls of NPP, not least the role of nutrient limitations, are inadequately understood and that this is a major impediment to the development of reliable ESMs.

Perusal of the terrestrial ecology literature confirms that there is indeed no consensus on the controls of either GPP or NPP. Some empirical primary production models have continued to rely on correlations with mean annual temperature and precipitation (Del Grosso et al., 2008), even though the positive geographic relationship of GPP or NPP with temperature is almost certainly indirect, rather than causative (Bonan, 1993; Garbulsky et al., 2010). There is a strong correlation between the latitudinal gradients of photosynthetically active radiation (PAR) and mean annual temperature; PAR is the driving force of photosynthesis but also constitutes a nearly constant fraction of solar short-wave radiation, which is the driving force of the latitudinal temperature gradient. It is therefore very likely that the observed global relationships of GPP and NPP to temperature are caused at least in part by this correlation between temperature and PAR. Based on a model simulation, Churkina and Running (1998) assessed the relative importance of different climatic controls (temperature, water availability, PAR) on terrestrial primary production, indicating different controls or combinations of controls to be dominant in different regions. However, the analysis by Churkina and Running implicitly discounts the possibility that all three factors could simultaneously limit photosynthesis, and ignores the ubiquitous, experimentally observed stimulation of $\mathrm{C}_{3}$ photosynthesis by increasing $\left[\mathrm{CO}_{2}\right]$. It has long since been established that agricultural crop production is proportional to the cumulative PAR absorbed by the crop (Monteith and Moss, 1977a; Monteith and Moss, 1977b), yet Pongratz et al. (2012) and others have modelled crop production without considering PAR. Many models have invoked N and/or P limitations as ancillary controls on primary production; Huston and Wolverton (2009) went further, arguing that soil nutrients (rather than climate) primarily determine the global pattern of NPP. Finally, Fatichi et al. (2013) claimed that NPP is not controlled by photosynthesis at all, but rather by environmental constraints on growth.

Different explanations of the controls of terrestrial primary production are thus rife in the ecological literature, yet the choice of model assumptions can imply radically different responses to global change (Wang et al., 2012). It is therefore time for a fundamental reassessment of the controls of primary production. With this goal in mind, we define a conceptually very simple model for GPP. The model allows us to explore the consequences (and potentially the limitations) of the hypothesis that "the primary controls on terrestrial GPP are incident PAR, green-vegetation cover and $\left[\mathrm{CO}_{2}\right]$ ". We first consider a counterfactual, continuously veg- etated world in which $\mathrm{C}_{3}$ photosynthesis operates at its full biophysical potential everywhere, and PAR is not attenuated by atmospheric absorption and clouds. Then, we add constraints one by one. The model has the form of a "light-use efficiency" (LUE) model (i.e. modelled GPP is proportional to absorbed PAR). However, unlike empirical LUE models, the value of LUE and its variation with environmental factors are derived from first principles, beginning with the standard model of $\mathrm{C}_{3}$ photosynthesis (Farquhar et al., 1980). The derivation rests on the "co-limitation" or "coordination" hypothesis, which predicts that the photosynthetic capacity of leaves at any location and canopy level acclimates over times longer than a day to the prevailing daytime PAR. This is in order to be neither in excess (which would entail additional, non-productive maintenance respiration) nor less than what is required for full exploitation of the available PAR. This hypothesis implies that average daily photosynthesis under field conditions is close to the point where the Rubisco- and electron transport-limited rates are equal. The co-limitation hypothesis has strong experimental support, as was recently demonstrated by Maire et al. (2012).

The LUE concept has been applied in diagnostic primary production models, including the Simple Diagnostic Biosphere Model, SDBM (Knorr and Heimann, 1995), the Carnegie-Ames-Stanford Approach model, CASA (Field et al., 1995; Potter et al., 1993), the Simple Diagnostic Photosynthesis and Respiration Model, SDPRM (Badawy et al., 2013), and the widely used algorithms to estimate GPP and NPP from remotely-sensed "greenness" data provided by MODIS (Running et al., 2004). By "diagnostic" we mean models that rely on remotely sensed green vegetation as an input, distinct from prognostic models that simulate vegetation cover. A particular version of the co-limitation hypothesis was used to derive an explicit LUE formula in the strand of complex, prognostic terrestrial carbon-cycle models that originated with BIOME3 (Haxeltine and Prentice, 1996) and the Lund-Potsdam-Jena (LPJ) DGVM (Sitch et al., 2003). $\mathrm{CO}_{2}$ limitation can be represented in a natural way in the co-limitation framework if the ratio of leaf-internal to ambient $\left[\mathrm{CO}_{2}\right]\left(c_{\mathrm{i}} / c_{\mathrm{a}}\right)$ can be specified. This is done here with the help of the "least-cost hypothesis" (Wright et al., 2003), which states that the long-term effective value of $c_{\mathrm{i}} / c_{\mathrm{a}}$ minimizes the combined unit costs of carboxylation (proportional to photosynthetic capacity) and transpiration (proportional to sapflow capacity). This hypothesis also has strong empirical support (Prentice et al., 2014) and provides a continuous prediction of the $c_{\mathrm{i}} / c_{\mathrm{a}}$ ratio as a function of environmental aridity, temperature and elevation. Thus, our modelling approach does not require that we divide plants into functional types (PFTs) with apparently differing physiological responses, as has usually been done in complex models, and is now commonly done in models based on remote sensing as well.

We focus exclusively on GPP. It is probably reasonable to extrapolate the first-order results to NPP, given that, on a global scale, NPP is approximately a constant fraction of 
Table 1. Model equations for each step and the global annual gross primary production (GPP, $\mathrm{Pg} \mathrm{Ca}^{-1}$ ) estimated by each model. $\varphi_{0}$ : intrinsic quantum efficiency of photosynthesis $\left(\mathrm{mol} \mathrm{mol}^{-1}\right)$, ã: leaf absorptance (dimensionless), PAR: incident photosynthetically active radiation $\left(\mathrm{mol} \mathrm{m}^{-2}\right), \mathrm{PAR}_{\mathrm{toa}}$ : PAR at the top of the atmosphere $\left(\mathrm{mol} \mathrm{m}^{-2}\right)$, PAR $_{0}$ : accumulated PAR for the period with daily temperature above $0{ }^{\circ} \mathrm{C}\left(\mathrm{mol} \mathrm{m}^{-2}\right)$, fAPAR: fractional absorbed PAR (dimensionless), $c_{\mathrm{i}}$ : leaf-internal $\mathrm{CO}_{2}$ concentration $\left(\mu \mathrm{mol} \mathrm{mol}{ }^{-1}\right)$, $\Gamma^{*}$ : photorespiratory compensation point $\left(\mu \mathrm{mol} \mathrm{mol}^{-1}\right)$.

\begin{tabular}{lr}
\hline Model equation & $\begin{array}{r}\text { Global } \\
\text { annual GPP }\end{array}$ \\
\hline $\mathrm{GPP}=\varphi_{0} \times \tilde{a} \times \mathrm{PAR}_{\text {toa }}$ & 2960 \\
$\mathrm{GPP}=\varphi_{0} \times \tilde{a} \times \mathrm{PAR}$ & 1442 \\
$\mathrm{GPP}=\varphi_{0} \times \tilde{a} \times \mathrm{PAR} \times \mathrm{fAPAR}$ & 322 \\
$\mathrm{GPP}=\varphi_{0} \times \tilde{a} \times \mathrm{PAR}_{0} \times \mathrm{fAPAR}$ & 300 \\
$\mathrm{GPP}=\varphi_{0} \times \tilde{a} \times \mathrm{PAR}_{0} \times \mathrm{fAPAR} \times \frac{c_{\mathrm{i}}-\Gamma^{*}}{c_{\mathrm{i}}+2 \times \Gamma^{*}}$ & 211 \\
\hline
\end{tabular}

GPP (Waring et al., 1998), although caution is needed because this fraction may vary (DeLUCIA et al., 2007). The fine-tuning of the NPP / GPP ratio is a separate issue, which will be considered in forthcoming work. $\mathrm{C}_{4}$ and CAM photosynthesis are not modelled. For this reason, evaluation of the model results is based on data from forests, where $\mathrm{C}_{3}$ photosynthesis predominates.

\section{Methods}

\subsection{Model summary and protocol}

The model was applied to the global land surface, excluding ice-covered regions and Antarctica, at a grid resolution of $0.5^{\circ}$. It was driven with a fixed seasonal cycle of PAR, climate and fAPAR. Insolation (short-wave solar radiation at the top of the atmosphere) was computed using standard methods. Half of solar short-wave radiation was assumed to be PAR. PAR was converted from energy to photon units using a conversion factor of $4.5 \mathrm{~mol}^{-1} \mathrm{MJ}$. Remotely sensed green-vegetation-cover data were used to derive absorbed PAR. Required climate data (mean monthly temperature, precipitation and fractional cloud cover) were derived from climatic research unit time-series data (CRU TS3.1), averaged over the same period as the remote-sensing measurements.

We first considered a hypothetical world in which PAR at the top of the atmosphere $\left(\mathrm{PAR}_{\text {toa }}\right.$, see more detailed calculations in Appendix, Sect. A1) could be fully utilized by plants. In other words, we assumed a continuous vegetation cover, ideal temperature and moisture conditions, and a perfectly clear atmosphere containing adequate $\mathrm{CO}_{2}$ for optimal photosynthesis (Table 1). Potential GPP under these conditions is the product of PAR toa, leaf absorptance $(a)$, and the intrinsic quantum efficiency of photosynthesis $\left(\varphi_{0}\right)$. The leaf absorptance accounts for the fraction of PAR lost by reflection (albedo), transmission and incomplete utilization of the PAR spectrum. We assumed a leaf absorptance of 0.8 (Collatz et al., 1998), bearing in mind that this quantity shows substantial variation among species (Long et al., 1993). The intrinsic quantum efficiency of photosynthesis is the quantum efficiency $\left(\mathrm{mol} \mathrm{mol}^{-1}\right)$ that can be realized at low PAR, low $\left[\mathrm{O}_{2}\right]$ and saturating $\left[\mathrm{CO}_{2}\right]$. We assigned an intrinsic quantum efficiency of 0.085, again following Collatz et al. (1998). This is in the mid-range of reported values for the intrinsic quantum efficiency of $\mathrm{C}_{3}$ photosynthesis.

As the real atmosphere is not perfectly clear and contains clouds, we considered next the effect of atmospheric absorp-

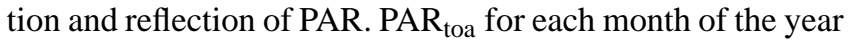
was converted to the PAR incident on vegetation canopies (Table 1) using the Prescott formula (Linacre, 1968). This modifies GPP by a factor of 0.75 (the clear-sky transmittivity) under clear skies, declining to 0.25 under completely cloudy skies. The values thus obtained were increased by $2.7 \%$ per kilometre of elevation (Allen, 2005) to account for the reduced thickness of the atmosphere at higher elevations (Appendix, Eq. A3).

The fraction of absorbed PAR (fAPAR), indicating actual green-vegetation cover, was introduced next. fAPAR is assumed to represent effects of limited water availability, low temperatures and nutrient deficits in reducing the NPP available for allocation to leaves, as well as the varying phenology and turnover time of leaves (Table 1). It was further assumed that fAPAR implicitly accounts for the differential penetration of diffuse and direct PAR into dense vegetation canopies (Mercado et al., 2009). We used the SeaWiFS fAPAR product (1998 to 2004) (Gobron et al., 2006), which we have previously used to drive the SDBM in a benchmarking study (Kelley et al., 2013). The extent to which different schemes deriving fAPAR from remotely sensed reflectance data account for the various losses included in ã is unclear. However, if fAPAR includes these losses, then values should nowhere exceed about 0.8, whereas the SeaWifS fAPAR reaches 1.0. Accordingly, we have retained ã in the expressions for GPP that include fAPAR. For the present application, we averaged different years' values for each month of the year to produce a monthly climatology of fAPAR. Missing values in winter were set to zero. The monthly values of fAPAR were used to multiply the monthly values of PAR.

In the next step, the inhibition of $\mathrm{CO}_{2}$ assimilation at low temperatures was described by a ramp function, reducing the utilization of PAR for photosynthesis linearly from 10 to $0^{\circ} \mathrm{C}$, with zero photosynthesis at daily temperatures below $0{ }^{\circ} \mathrm{C}$. Daily values of PAR were thus integrated over the month to give monthly $\mathrm{PAR}_{0}$, as defined in Table 1 . $\mathrm{PAR}_{0}$ is a weighted monthly PAR, with the weighting provided by the ramp function (Eqs. A4, A5).

The final step accounts for the effect of photorespiration and substrate limitation at subsaturating $\left[\mathrm{CO}_{2}\right]$, based on the Farquhar model (Table 1). GPP was reduced by the factor $\left(c_{\mathrm{i}}-\Gamma^{*}\right) /\left(c_{\mathrm{i}}+2 \Gamma^{*}\right)$, where $\Gamma^{*}$ is the photorespiratory 
compensation point. The co-limitation hypothesis equates the Rubisco- and electron-transport limited rates of photosynthesis. We use the electron-transport limited rate as this yields an estimate of LUE. We neglect $J_{\max }$ limitation, thus making the approximation that Rubisco is always limiting at high PAR. The temperature dependence of $\Gamma^{*}$ was described by an Arrhenius function (Bernacchi et al., 2003), evaluated at the growing-season mean temperature $\left(\mathrm{mGDD}_{0}\right) \cdot \mathrm{mGDD}_{0}$ is defined as the annual sum of temperatures above $0{ }^{\circ} \mathrm{C}$ (GDD - growing degree days) divided by the length of the period with temperatures above $0^{\circ} \mathrm{C}$. $c_{\mathrm{i}}$ was derived from the ratio of $c_{\mathrm{i}} / c_{\mathrm{a}}$, which was predicted as a function of $\mathrm{mGDD}_{0}$, atmospheric aridity $(\Delta E)$ and elevation, based on the leastcost hypothesis (Prentice et al., 2014). $\Delta E$ is the cumulative annual difference between actual and equilibrium evapotranspiration, where actual evapotranspiration is computed using a quasi-daily soil-moisture accounting scheme (Cramer and Prentice, 1988). This measure is approximately proportional to the effective growing-season average value of vapourpressure deficit experienced by the plants (see Prentice et al., 2014, Supporting Information, for a derivation). Further details on the calculation of $c_{\mathrm{i}} / c_{\mathrm{a}}$ and $\Gamma^{*}$ are given in Sects. A4 and A5, respectively.

\subsection{Driving data}

PAR, $\mathrm{PAR}_{0}, \mathrm{mGDD}_{0}$ and $\Delta E$ were calculated from insolation and climate data with a modified version of a simple process-based bioclimatic model (STASH) model (Gallego-Sala et al., 2010; Sykes et al., 1996). STASH was modified to account for the effects of elevation on atmospheric transmittivity and the effect of atmospheric pressure on the psychrometer constant, used in the calculation of equilibrium evapotranspiration (http://www.fao.org/docrep/ X0490E/x0490e07.htm). The algorithm to compute insolation was also revised to more accurately compute celestial longitude (the angle between the Earth's position and its position at the vernal equinox) on each day of the year, given the orbital parameters (eccentricity, obliquity and precession). The method of Kutzbach and Gallimore (1988) was used to represent the effect of precession. This modification has little effect under the present-day orbital configuration. Elevations were taken to be the mean elevations of each grid cell as given by CRU (http://www.cru.uea.ac.uk/). The ambient $\left[\mathrm{CO}_{2}\right]$ was set at its mean value during the period 1998 to $2005\left(370 \mu \mathrm{mol} \mathrm{mol}^{-1}\right)$.

\subsection{Analysis of annual fAPAR data}

In order to clarify how environmental variables affect the global GPP pattern through fAPAR, we performed a supplementary analysis of the controls of annual fAPAR. Annual fAPAR was calculated as a weighted average of the monthly values, the weighting provided by the mean monthly incident PAR, neglecting periods with mean temperatures below
$0{ }^{\circ} \mathrm{C}$ (as described in Kelley et al., 2013). We carried out an ordinary linear regression of fAPAR against the $\alpha$ coefficient (ratio of actual to equilibrium evapotranspiration) calculated as in Cramer and Prentice (1988) and Gallego-Sala et al. (2010), modified as described above. We also performed a generalized linear model analysis using $\alpha$ and $\mathrm{mGDD}_{0}$, then $\alpha, \mathrm{mGDD}_{0}$ and total soil cation exchange capacity from the ISRIC-WISE gridded data set (Batjes, 2009) as predictors of fAPAR.

\subsection{GPP data-model comparisons}

GPP predictions from the final modelling step were compared to the global synthesis of annual GPP measurements from forests by Luyssaert et al. (2007). The model's prediction of global GPP was compared with the range of published, observationally based estimates (Beer et al., 2010).

Modelled seasonal cycles of GPP were compared with seasonal cycles of gap-filled GPP derived from eddy covariance measurements of $\mathrm{CO}_{2}$ exchange in the FLUXNET archive (http://www.fluxdata.org/). In all, 146 flux towers in FLUXNET have publicly available data between 2002 and 2006. We used all of these data. Half-hourly measurement pairs of net ecosystem exchange (NEE) and photosynthetic photon flux density (PPFD) (equivalent to PAR, in photon units) were partitioned into GPP and ecosystem respiration by fitting the rectangular hyperbola response model as presented by Ruimy et al. (1995) (their Eq. 27). A non-linear least-squares regression was performed on each monthly set of NEE-PPFD observation pairs at each tower, after anomalous data points (identified using Peirce's criterion) had been deleted. Monthly totals of GPP were then calculated as follows: first, each PPFD time series was completed using a gap-filling product based on a half-hourly calculation of solar radiation at the top of the atmosphere, scaled down in magnitude by daily observations of short-wave downwelling solar radiation, as provided by the WATCH forcing data based on the ERA Interim reanalysis (Weedon et al., 2012). Then, the gap-filled PPFD data were converted to GPP using the model-fitted parameters for each month and tower, and cumulated to monthly totals. Months for which the data could not be fitted with a rectangular hyperbola were excluded from analysis.

\section{Results}

\subsection{Model predictions: annual GPP}

The patterns and total values of global annual GPP show a progressive reduction during the course of imposing biophysical and ecophysiological constraints (Fig. 1, Table 1). Potential GPP based on PAR toa varies only with latitude, being maximal at the equator and declining smoothly towards the poles (Fig. 1a). The decline is almost, but not quite, symmetrical. The southern hemisphere shows slightly higher values 
at any given latitude because the Earth is currently nearest to the Sun in northern winter (southern summer).

The strict latitudinal pattern of potential GPP is altered by cloud cover (Fig. 1b). Values are lowered around the equator and at high latitudes due to cloudiness. The highest values are found in subtropical deserts. The combined effects of atmospheric absorption and clouds reduce total global annual GPP by nearly half (Table 1 ).

The largest drop by about $78 \%$ in modelled GPP occurs at the next step (Fig. 1c) due to the introduction of fAPAR. Obvious modifications include the effects of low water availability in desert regions. fAPAR values of unity are restricted to very few locations (e.g. subantarctic islands). Forested regions typically have fAPAR values in the range 0.2 to 0.8 . The moisture indicator $\alpha$ alone accounted for $45 \%$ of the variance in annual fAPAR. This figure rose to $54 \%$ after inclusion of $\mathrm{mGDD}_{0}$ as an additional predictor, and to $55 \%$ after inclusion of soil cation exchange capacity. All three predictors had highly significant effects $(P<0.001)$.

Additional effects of temperature limitation, introduced after the influence of fAPAR has been taken into account, further diminish GPP only in the regions of the world (temperate, boreal, polar and high-mountain regions) that routinely experience cold conditions (Fig. 1d). The reduction in global total annual GPP (Table 1) at this step is only about $7 \%$.

The effects of subsaturating $\left[\mathrm{CO}_{2}\right]$ in limiting GPP (with fAPAR held constant) are also relatively slight (30\%), but pervasive across terrestrial ecosystems (Table 1). The strongest $\mathrm{CO}_{2}$ constraint on GPP is predicted for hot and dry regions, such as the Australian deserts; the weakest constraint is predicted for cold and humid regions, such as eastern Siberia (Fig. 1e).

Elevation effects are slight in a global perspective, although significant locally. A sensitivity test showed that increasing the elevation of the global land surface by $4000 \mathrm{~m}$, with all other factors unchanged, would increase global GPP by $7 \%$. The net effect is positive because the thinner atmosphere (greater PAR transmission) and reduced partial pressure of $\mathrm{O}_{2}$ (implying a greater affinity of Rubisco for $\mathrm{CO}_{2}$ ) at high elevations more than counteract the negative effects of the reduced psychrometer constant (increased water loss) and the reduced partial pressure of $\mathrm{CO}_{2}$.

\subsection{Data-model comparisons: annual GPP}

Comparison with the Luyssaert et al. observations on annual GPP indicates a satisfying model prediction at the high end (tropical forests), but a general tendency to overestimate GPP in temperate and boreal forests (Fig. 2). The predicted global total GPP value $\left(211 \mathrm{Pg} \mathrm{Ca}^{-1}\right)$ lies above the range of $123 \pm 8 \mathrm{Pg} \mathrm{Ca}^{-1}$ provided by Beer et al. (2010) based on eddy covariance flux data and various diagnostic models, and also above the value of Welp et al. (2011), 150-175 $\mathrm{Pg} \mathrm{Ca}^{-1}$, inferred from oxygen isotope data. Nevertheless, inspection of Fig. 2 suggests that the model approximates a "boundary
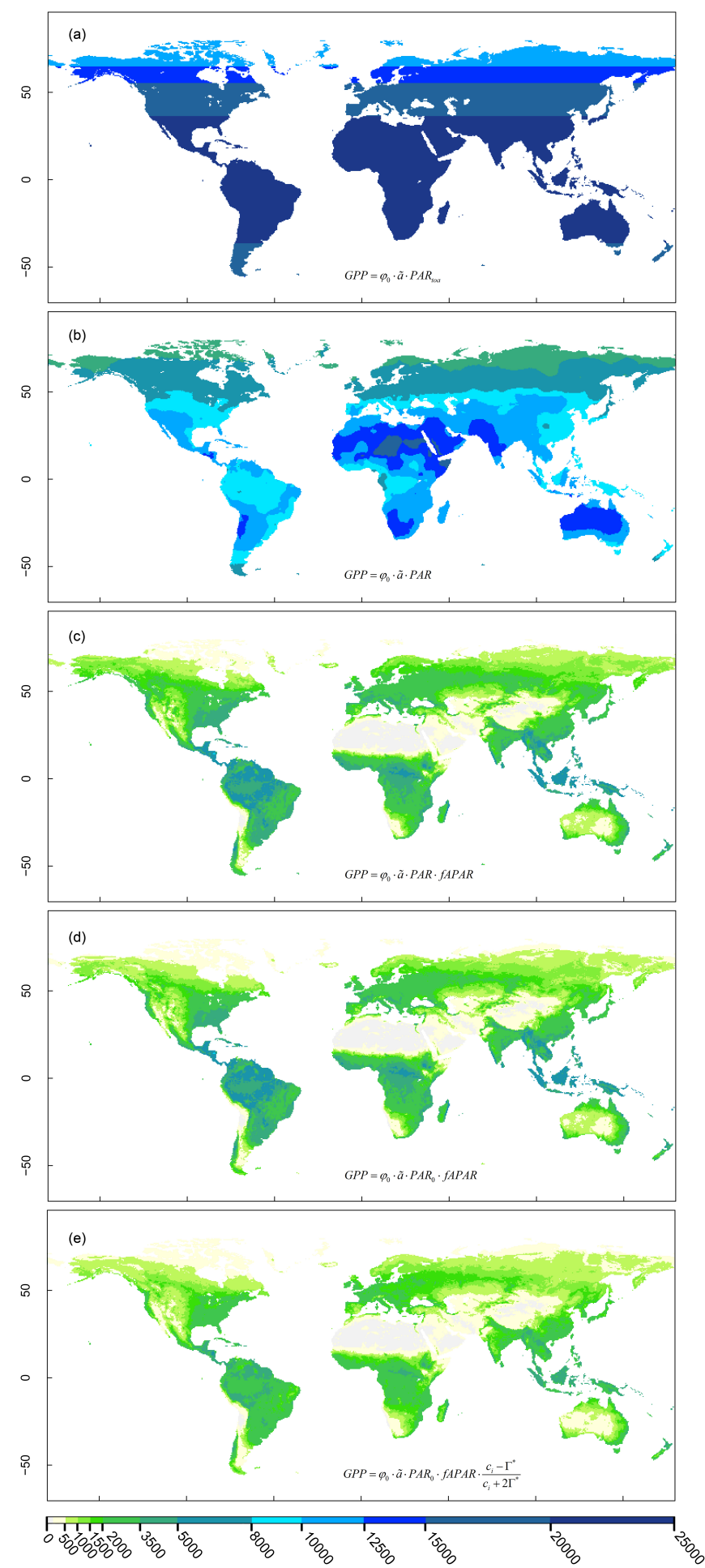

Figure 1. The patterns of modelled global annual GPP $\left(\mathrm{g} \mathrm{C} \mathrm{m}^{-2} \mathrm{a}^{-1}\right)$ controlled by PAR at the top of atmosphere (a), and modified by a sequence of effects: atmospheric transmissivity and cloud cover (b), foliage cover (c), low-temperature inhibition (d) and $\mathrm{CO}_{2}$ limitation (e). 


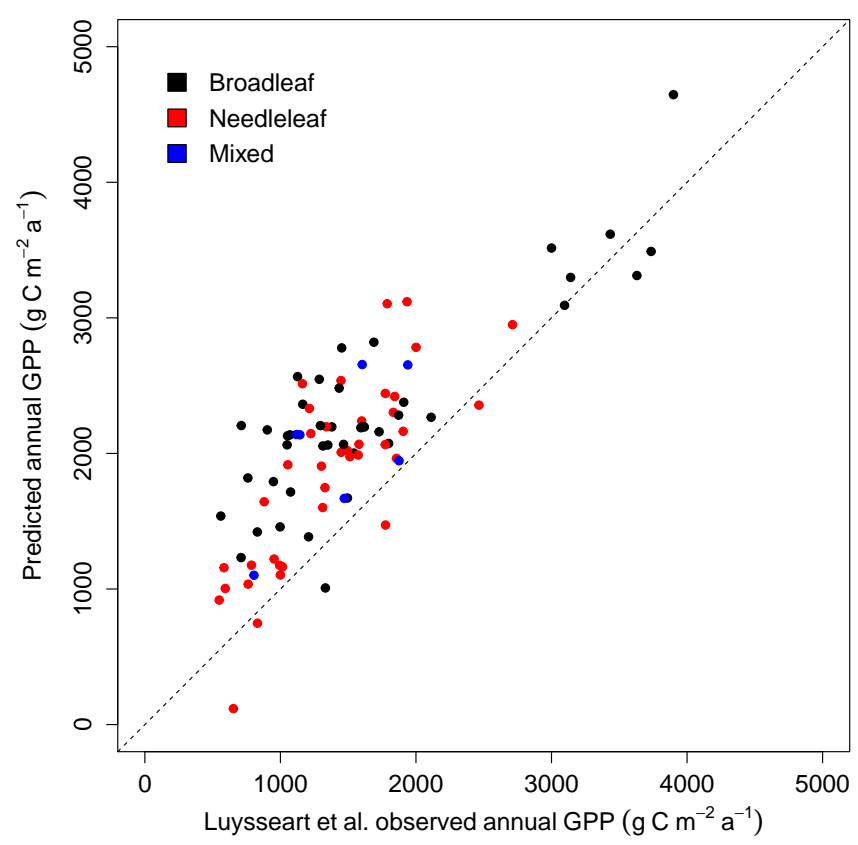

Figure 2. Relationship between observed annual GPP from Luyssaert et al. (2007) and predicted annual GPP.

line" for temperate and boreal-forest GPP. A few sites show GPP close to that modelled, but many others show GPP lower than this. In other words, the model appears to be predicting an upper bound for GPP, which is not always achieved in the field. There is no systematic difference between broadleaf and needleleaf forests in the extent to which the model overpredicts GPP.

\subsection{The seasonal maximum of GPP}

Although the greatest annual GPP is both predicted and observed for tropical moist forests (Figs. 1, 2), the GPP achieved during the month with maximum GPP can be as high or higher in boreal or temperate forests. This tendency is shown both by model predictions (Fig. 3) and flux observations (Fig. 4). Tropical evergreen broadleaf forests have high GPP throughout the year, with a muted seasonal cycle reflecting the alternation of wetter and drier seasons (Fig. 4). The estimated average annual GPP of $2760 \mathrm{~g} \mathrm{C} \mathrm{m}^{-2} \mathrm{a}^{-1}$ marks tropical forests as the most productive, but the maximum monthly GPP in tropical evergreen broadleaf forests (about $300 \mathrm{~g} \mathrm{C} \mathrm{m}^{-2}$ month $\left.^{-1}\right)$ is exceeded by forests in the temperate zone (Fig. 4). The highest mean monthly GPP values in our flux data set are $358 \mathrm{~g} \mathrm{C} \mathrm{m}^{-2}$ month $^{-1}$ in a temperate evergreen needleleaf forest and $484 \mathrm{~g} \mathrm{C} \mathrm{m}^{-2}$ month $^{-1}$ in a temperate deciduous broadleaf forest. The monthly maximum GPP in boreal forests (in June or July), the lower quartile for temperate deciduous broadleaf forest, and the upper quartile for temperate evergreen and mixed forests are similar
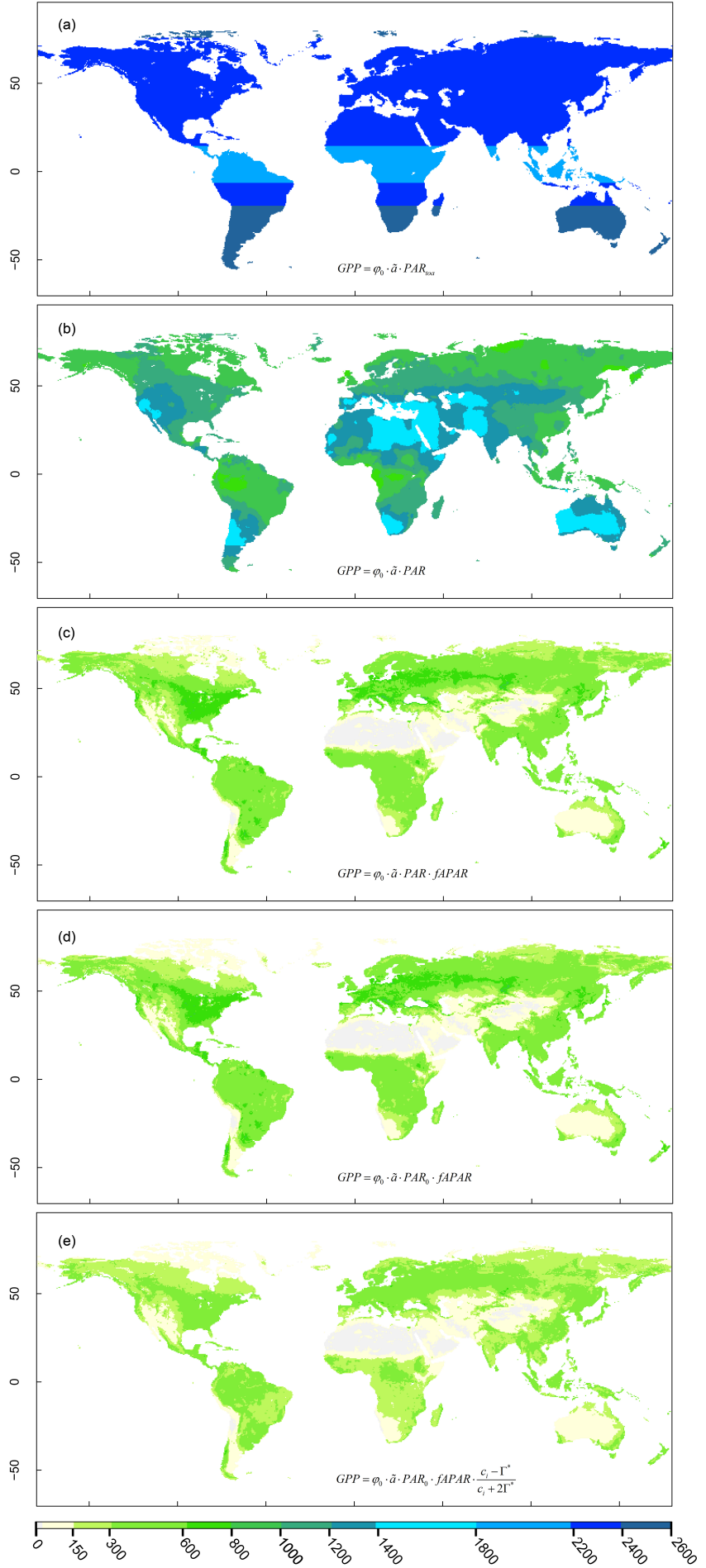

Figure 3. The patterns of modelled global maximum monthly GPP $\left(\mathrm{g} \mathrm{C} \mathrm{m}^{-2}\right.$ month $^{-1}$ ) controlled by PAR at the top of the atmosphere and modified by a sequence of effects, as in Fig. 1.

to, or even larger than, the maximum for tropical evergreen broadleaf forests. 


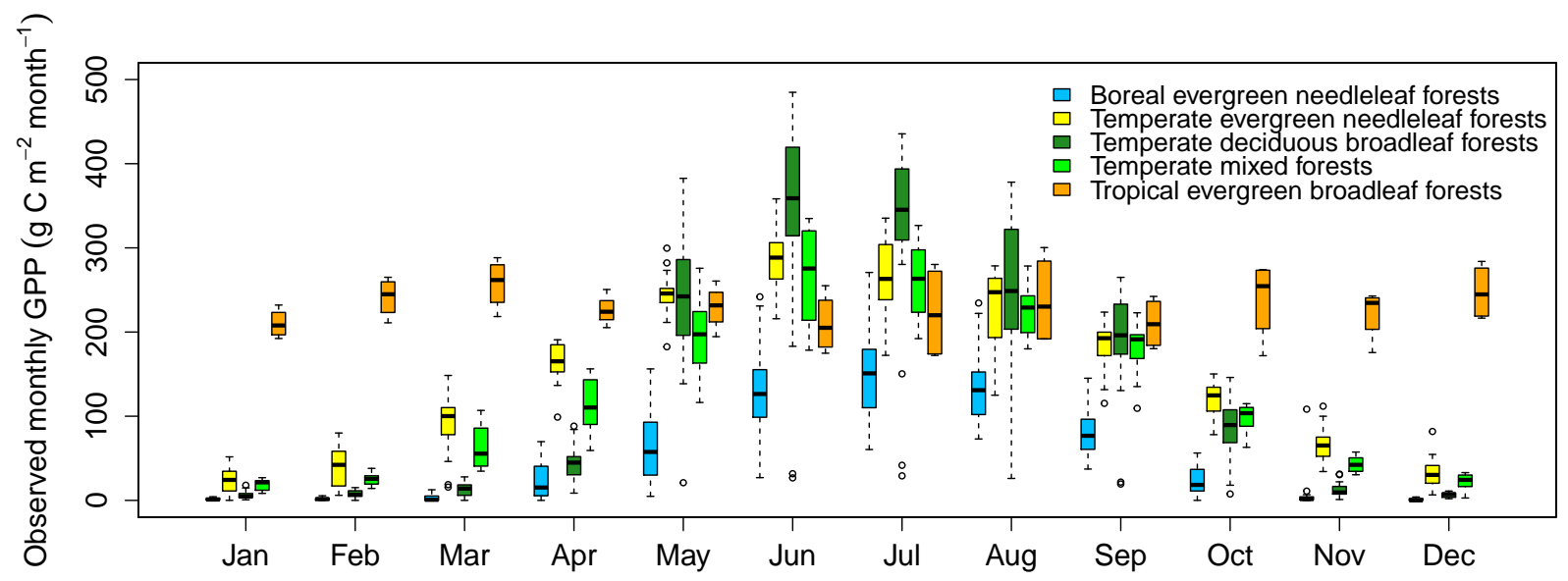

Figure 4. Box-and-whisker plot of monthly GPP $\left(\mathrm{g} \mathrm{C} \mathrm{m}^{-2}\right.$ month $\left.^{-1}\right)$ versus month, based on gap-filled GPP observations derived from the freely available measurements in the FLUXNET archive. The bottom of the box is the lower quartile and the top is the upper quartile. The whiskers extend to the lower and upper extremes, beyond which outliers are plotted as dots.

Figure 3 provides a biophysically based prediction of this phenomenon. In the top panel, it is already clear that the maximum monthly potential GPP - being proportional to insolation - is greatest in high latitudes, declining towards the equator. This is because the day length in high-latitude summer more than compensates for the low sun angles. The maximum daily insolation at any place and time on the Earth's surface occurs near the polar circles in the days around the summer solstice in each hemisphere. High cloud cover (Fig. 3b), low vegetation cover (Fig. 3c) and low temperatures (Fig. 3d) all tend to reduce the maximum monthly GPP in the Arctic, but the basic pattern persists (Fig. 3e) even after all constraints are included, allowing high maximum monthly GPP - comparable to or higher than that in tropical forests - to be achieved in boreal or temperate forests. The highest values of maximum monthly GPP $\left(>600 \mathrm{~g} \mathrm{C} \mathrm{m}^{-2} \mathrm{a}^{-1}\right)$ are predicted for certain mid-latitude temperate and boreal forest regions, including the Caucasus and Altai mountains.

\section{Discussion}

\subsection{Key patterns explained}

Our simple model predicts, among other things, that GPP in the summer months can be as high as or higher in boreal or temperate forests than it is in tropical forests. This prediction is supported by flux data (Fig. 4) and consistent with analyses of NPP data by Kerkhoff et al. (2005) and Huston and Wolverton (2009). Huston and Wolverton (2009) attributed this pattern to the prevalence of highly weathered, nutrientpoor soils in the tropics. Our explanation is simpler, based on the latitudinal and seasonal distribution of insolation and cloud cover combined with the physiology of photosynthesis. Although it is possible that variations in soil nutrient sta- tus are reflected, to some extent, in fAPAR with allocation to leaves being reduced and allocation to fine roots increased under low-nutrient conditions (Poorter et al., 2012), the fact that temperate forests do not consistently have lower fAPAR than tropical forests suggests that this effect is not predominant. However, our analysis of the controls of fAPAR suggests dominant control by climate, principally water supply, with smaller contributions from growing-season temperature (reduced fAPAR in cold climates) and soil properties.

We therefore argue that the first-order latitudinal patterns of GPP and its seasonal cycle are ultimately determined astronomically by the distribution of insolation. Due to the obliquity of the Earth's axis relative to the ecliptic, the latitude at which the Sun is directly overhead swings between the Tropics of Cancer and Capricorn, crossing the equator twice a year. The tropics therefore receive maximum annual insolation. But the maximum insolation in any one month shows a very different pattern, with highest values at high latitudes. At latitudes $>50^{\circ}$ in both hemispheres, the high maximum monthly insolation is counteracted in its effect on GPP by high cloud cover and seasonally low temperatures. High incident and absorbed PAR are experienced widely in summer in boreal and temperate latitudes, resulting in a high seasonal GPP. Our model is nonetheless consistent with total annual GPP being highest in tropical forests, due to relatively high insolation combined with adequate temperature and moisture conditions that persist throughout the year.

A novel feature of the model is its inclusion of elevation effects on GPP. Elevation affects GPP in several ways. Enhanced PAR is a direct result of a reduced path length through the atmosphere. Reduced stomatal conductance and $c_{\mathrm{i}} / c_{\mathrm{a}}$ ratios (and correspondingly higher photosynthetic capacity) are predictions of the least-cost hypothesis. These predictions have long-standing empirical support (Friend et al., 1989; Körner and Diemer, 1987), but are accounted for 
here as a consequence of the reduced partial pressure of $\mathrm{O}_{2}$, which lowers the cost of carboxylation relative to transpiration. On the other hand, the reduced psychrometer constant tends to increase $\Delta E$. The net effect in our model, ceteris paribus, is that GPP increases with elevation. The global effect is small, but the prediction would be worth exploring in the context of elevational transects. It has implications, especially for primary production in high-mountain regions in the tropics and subtropics.

\section{2 $\left[\mathrm{CO}_{2}\right]$ and nutrient supply effects}

We have implicitly assumed that fAPAR is independent of $\left[\mathrm{CO}_{2}\right]$. Thus, the effect of the final constraint - where the effect of subsaturating $\mathrm{CO}_{2}$ and, with it, the effect of restrictions on $c_{\mathrm{i}}$ and GPP due to stomatal closure in dry environments are added - reflects only the effects of $\left[\mathrm{CO}_{2}\right]$ on the rate of photosynthesis that could be achieved on the assumption of unchanging vegetation cover. The resulting prediction is a relatively modest potential for increased GPP with increasing $\left[\mathrm{CO}_{2}\right]$, following the $A-c_{\mathrm{i}}$ curve for electron transport-limited photosynthesis. A sensitivity analysis in which $\left[\mathrm{CO}_{2}\right]$ was elevated by $200 \mu \mathrm{mol} \mathrm{mol}^{-1}$ yielded a 5 to $25 \%$ stimulation of modelled annual GPP: on average smaller than the mean effect reported for temperate forest NPP (23 $\pm 2 \%)$ by Norby et al. (2005), based on FreeAir Carbon-dioxide Enrichment (FACE) experiments. This analysis also suggested a strong relationship between $\mathrm{CO}_{2}$ fertilization and temperature with warm areas experiencing stronger $\mathrm{CO}_{2}$ fertilization. Annual GPP was predicted to increase by about $18 \%$ across the tropics but by no more than $12 \%$ in the high latitudes of both hemispheres. The relationship to temperature is much less marked than in the analysis by Hickler et al. (2008), because the LPJ-GUESS model used there did not account for the response of $c_{\mathrm{i}} / c_{\mathrm{a}}$ to temperature. In our model, lower $c_{\mathrm{i}} / c_{\mathrm{a}}$ at lower temperatures implies a strengthening of the response to $c_{\mathrm{a}}$ because of the convexity of the $A-c_{\mathrm{i}}$ curve. This strengthening partially counteracts the temperature effect on $\Gamma^{*}$, which tends to produce a stronger $\mathrm{CO}_{2}$ response at higher temperatures.

Additional effects, not considered here, could modify these model predictions. One is the possible increase of fAPAR resulting from "water saving" by reduced stomatal conductance at increased $\left[\mathrm{CO}_{2}\right]$. Evidence has been presented for an increase of fAPAR, independently of precipitation trends, in warm and dry regions (Donohue et al., 2013). Such an increase would also tend to counteract any possible increase in runoff due to increasing $\left[\mathrm{CO}_{2}\right]$ (Ukkola and Prentice, 2013; Wang et al., 2012).

Another neglected effect is the possible restriction of $\left[\mathrm{CO}_{2}\right]$ fertilization due to exacerbated nutrient shortages, which would reduce the potential for GPP to be influenced by $\left[\mathrm{CO}_{2}\right]$. For example, there is evidence for a decline in $\mathrm{CO}_{2}-$ induced growth enhancement over the timescale of stand development in the Oak Ridge temperate forest FACE exper- iment (Norby et al., 2010), which appears to be a result of accelerated $\mathrm{N}$ depletion under $\mathrm{CO}_{2}$ enhancement. On the other hand, a comparative FACE study of grasslands showed photosynthetic responses to enhanced $\left[\mathrm{CO}_{2}\right]$ to be independent of $\mathrm{N}$ supply (Lee et al., 2011). A possible resolution of apparently conflicting results on the nutrient dependence of primary production (and, by extension, the $\left[\mathrm{CO}_{2}\right]$ effect) would depend on the responses of GPP, NPP and biomass growth being distinguished (note that NPP includes components such as root exudation and volatile organic compound emission that do not directly contribute to biomass growth). Vicca et al. (2012) showed no difference in GPP between forests on fertile and infertile soils, and no evidence for differences in the NPP / GPP ratio, but a very large difference in biomass growth, suggesting that the key difference lies in the allocation of NPP to supporting root symbionts that assist trees in acquiring nutrients under conditions of low nutrient availability. This finding is consistent with that of Aoki et al. (2012), who measured, with results that were many times greater, exudation of organic acids from tropical trees on soils with low $\mathrm{P}$ availability, relative to more fertile soils in the same climate. The effect apparently extends to wholeecosystem carbon uptake, which was shown by FernándezMartínez et al. (2014) to be determined by nutrient availability to a far greater extent than GPP. These various findings suggest that the current paradigm for the inclusion of nutrient reponses in complex ecosystem models - whereby nutrient supplies influence photosynthetic rates, and thence NPP and biomass growth - is incorrect, and that the way forward will involve explicit modelling of how carbon allocation (to roots versus shoots and to investment in nutrient acquisition versus biomass growth) is influenced by nutrient availability.

\subsection{Implications for modelling strategy}

Global LUE models have a history dating back at least to the early 1990s, with the publication of the widely used Carnegie-Ames-Stanford Approach model, CASA (Field et al., 1995; Potter et al., 1993), and the SDBM (Knorr and Heimann, 1995) to predict NPP. Models based on the LUE principle continue to be developed and compared, now most commonly in terms of their ability to reproduce GPP as derived from $\mathrm{CO}_{2}$ flux measurements (see e.g. Cheng et al., 2014; McCallum et al., 2009, 2013; Verma et al., 2014; Horn and Schulz, 2011; Yuan et al., 2007, 2013). Their popularity depends on the fact that green-vegetation cover in LUE models is directly provided from satellite observations, thus sidestepping one of the most serious limitations of current dynamic global vegetation models (DGVMs), namely their (in)ability to realistically predict spatial and temporal patterns of green-vegetation cover (Kelley et al., 2013). Despite persistent differences among different satellite-derived fAPAR products (McCallum et al., 2010), the physical definition of fAPAR is clear, and remotely sensed fAPAR values can be evaluated and ultimately improved by systematic 
comparison with in situ measurements (Pickett-Heaps et al., 2014).

On the other hand, reliable projection of the effects of future $\left[\mathrm{CO}_{2}\right]$ and climate changes demands that fAPAR also be predicted from first principles. There must be a feedback from NPP to fAPAR, because sufficient NPP is required to sustain a given leaf area. Current DGVMs model this feedback implicitly, but there has been little effort to evaluate their predictions of fAPAR and its response to environmental changes. When tested, models have been found wanting (e.g. Kelley et al., 2013; Keenan et al., 2014). Process-based prediction of fAPAR is an important goal for further research and presumably a feasible one, given the ready availability of fAPAR observations as a target.

Meanwhile, the multiplicity of available LUE formulations, and the lack of agreement on, for example, the way temperature and $\mathrm{CO}_{2}$ responses are built into LUE models (Verma et al., 2014), or whether or not these responses should be PFT-specific (Yuan et al., 2013), are causes for concern. These differences ultimately reflect the lack of a clear theoretical basis for LUE modelling. In this paper, we have attempted to provide such a basis through the adoption of two optimality hypotheses with independent empirical support, namely the co-limitation hypothesis (Maire et al., 2012), which predicts that LUE is determined by the electron-transport limited rate of photosynthesis according to the Farquhar model, and the least-cost hypothesis (Prentice et al., 2014), which provides an explicit prediction of $c_{\mathrm{i}} / c_{\mathrm{a}}$ ratios as a function of the physical environment. Our model makes the further explicit assumptions that (a) the controls of LUE are universal in all $\mathrm{C}_{3}$ plants (thus, we do not distinguish among PFTs), and (b) soil moisture and nutrient availability constraints on GPP are mediated by fAPAR and thus do not influence LUE.
As a result of these hypotheses and assumptions, the model has far fewer parameters than most. Aside from constants, such as the intrinsic quantum efficiency of photosynthesis, that are independently measured to within $\pm 10 \%$ or better, the model has just one parameter $-C$ in equation A7 - that has to be estimated (and we have also done this from independent observations). Moreover, the model's explicit relationship to the Farquhar model of photosynthesis allows a natural way to include the effect of changes in $\left[\mathrm{CO}_{2}\right]$, requiring no additional parameters to be specified - in contrast with, for example, Los et al.'s (2013) modification of CASA to include a $\mathrm{CO}_{2}$ response, which is otherwise missing from the CASA model.

It is commonly impossible to discern the extent to which parameter values in complex models have been tuned to data that may then be used to evaluate their performance. However, many models contain "hidden" parameters whose values are not traceable to measurements. For example, the temperature response equations of LUE in CASA (Potter et al., 1993) contain six hard-wired numerical constants, in addition to the maximum LUE for NPP $\left(\varepsilon^{*}\right)$ that is explicitly calibrated. The LPJ model (Sitch et al., 2003) similarly contains PFT-specific temperature "envelope" responses of unclear provenance and reliability. This situation reflects the data-poor world into which models such as CASA and LPJ were born. More recently developed models are often simpler, with process formulations derived more directly from observations such as flux measurements. The model presented here represents a further step towards simplicity and traceability which, we suggest, will be necessary attributes of "next-generation" ecosystem models. 
Appendix A: Estimation of biophysical constraints in the model

\section{A1 PAR at the top of the atmosphere}

Instantaneous incoming solar radiation (insolation) on a horizontal surface at the top of the atmosphere is given by

$Q=Q_{\mathrm{sc}} \times d_{\mathrm{r}} \times(\sin l \times \sin \delta+\cos l \times \cos \delta \times \cos h)$.

Here, $Q_{\mathrm{sc}}$ is the solar constant $\left(1369 \mathrm{~W} \mathrm{~m}^{-2}\right)$ (Willson and Mordvinov, 2003), $d_{\mathrm{r}}$ is the inverse square of the relative Sun-Earth distance (dimensionless), $l$ is latitude in radians, $\delta$ is solar declination in radians and $h$ is the "hour angle" (the time before or after solar noon in radians). We use formulae based on the day number to obtain $d_{\mathrm{r}}$ and $\delta$. We assume that, over the course of 1 day, there is effectively no variation in $d_{\mathrm{r}}$ or $\delta$. As $Q_{\mathrm{sc}}$ and $l$ do not vary either, we can obtain daily insolation by integrating with respect to $h$ between the hours of sunrise and sunset. The result is

$$
\begin{aligned}
& Q=\frac{86400}{\pi} \times Q_{\mathrm{sc}} \times d_{\mathrm{r}} \times\left(h_{\mathrm{s}} \times \sin l \times \sin \delta+\cos l\right. \\
& \left.\times \cos \delta \times \sin h_{\mathrm{s}}\right),
\end{aligned}
$$

where $h_{\mathrm{s}}$ is the hour angle of sunset, given by $h_{\mathrm{s}}=\arccos$ $[-\tan l \tan \delta] .86400$ is the number of seconds in a day. The term in square brackets is set to 1 if it exceeds 1 , or -1 if it becomes less than -1 , which are the special cases of polar day and night.

Daily total PAR at the top of the atmosphere is taken to be $0.5 Q\left(\mathrm{~J} \mathrm{~m}^{-2}\right)$, which is then converted to quantum units $\left(\mathrm{mol} \mathrm{m}^{-2}\right.$ ) using the factor $4.5 \mathrm{~mol} \mathrm{MJ}^{-1}$ (a spectrally averaged value for the energy content of $1 \mathrm{~mol}$ of photosynthetically active photons). Quantum units are preferred because photosynthesis depends on the absorption of a given number of quanta, rather than a given amount of electromagnetic energy. LUE is thus a dimensionless quantity.

\section{A2 Atmospheric transmissivity and cloud cover}

Daily solar short-wave radiation $\left(R_{\mathrm{SW} \downarrow}\right)$ is given by a modification of the Prescott formula:

$$
R_{\mathrm{SW} \downarrow}=Q \times\left(0.25+0.5 \times n_{\mathrm{i}}\right) \times(1+0.027 \times z),
$$

where $n_{\mathrm{i}}$ is the daily fractional hours of bright sunshine (dimensionless), which we equate with the one-complement of fractional cloud cover, as given in the CRU TS3.1 data set, and $z$ is elevation $(\mathrm{km})$ above sea level. The last term in Eq. (A3) is a correction for the thinning of the atmosphere with increasing elevation.

\section{A3 Low-temperature inhibition}

Low-temperature inhibition of photosynthesis is accounted for by weighting daily values of PAR $\left(\mathrm{PAR}_{\mathrm{d}}\right)$ in the accumulation of PAR over a month. We denote the weighted monthly
PAR by $\mathrm{PAR}_{0}$. The weighting is calculated as follows:

$$
\begin{aligned}
\mathrm{PAR}_{0 \mathrm{~d}} & =0 T_{\mathrm{d}} \leq 0^{\circ} \mathrm{C}, \\
\mathrm{PAR}_{0 \mathrm{~d}} & =\mathrm{PAR}_{\mathrm{d}} \times \frac{T_{\mathrm{d}}}{10} 0{ }^{\circ} \mathrm{C}<T_{\mathrm{d}}<10^{\circ} \mathrm{C}, \\
\mathrm{PAR}_{0 \mathrm{~d}} & =\mathrm{PAR}_{\mathrm{d}} T_{\mathrm{d}} \geq 10^{\circ} \mathrm{C},
\end{aligned}
$$

where $\mathrm{PAR}_{0 \mathrm{~d}}$ is the weighted daily PAR, and $T_{\mathrm{d}}\left({ }^{\circ} \mathrm{C}\right)$ is daily temperature, giving

$\operatorname{PAR}_{0}=\sum_{d=1}^{m} \operatorname{PAR}_{0 \mathrm{~d}}$

where $m$ is the total number of days in the month.

\section{A4 Leaf-internal $\left[\mathrm{CO}_{2}\right]$}

The "least-cost" hypothesis states that the sum of the unit costs of maintaining carboxylation and transpiration capacities is minimized. To a good approximation, this applies when the long-term effective value of $c_{\mathrm{i}} / c_{\mathrm{a}}$ is given by $\xi /(\xi+\sqrt{ } D)$ (Prentice et al., 2014). Here, $D$ is an annual effective growing-season value of the atmospheric vapourpressure deficit $(\mathrm{Pa})$ and $\xi$ is given by $\sqrt{ }(b K / 1.6 a)$, where $K$ is the effective Michaelis-Menten coefficient for Rubiscolimited photosynthesis $(\mathrm{Pa})$. The cost factor $b$ is the (assumed conservative) dimensionless ratio of leaf maintenance respiration to Rubisco carboxylation capacity; the cost factor $a$ is the dimensionless ratio of sapwood maintenance respiration to transpiration capacity, which is expected to increase with plant height $(H$, in $\mathrm{m})$ and the dynamic viscosity of water $(\eta$, in Pa s), according to Eq. (11) in Prentice et al. (2014).

Here, we express $a$ as the product of $\mathrm{H}^{2}, \eta$ and a constant $\left(a_{\mathrm{ref}}\right)$, allowing the equation for optimal $c_{\mathrm{i}} / c_{\mathrm{a}}$ to be re-written as

$$
\frac{c_{\mathrm{i}}}{c_{\mathrm{a}}}=\frac{1}{1+\sqrt{\frac{1.6 \times a_{\text {ref }} \times \eta \times D}{b \times K}} \times H} .
$$

We put the constant terms $\left(1.6, a_{\text {ref }}\right.$ and $\left.b\right)$ together outside the square root and denote them collectively as $C$. Equation A6 can then be simplified to

$$
\frac{c_{\mathrm{i}}}{c_{\mathrm{a}}}=\frac{1}{1+C \times \sqrt{\frac{\eta \times D}{K}} \times H} .
$$

Using a satellite-derived global data set on vegetation height (Simard et al., 2011), we performed a multiple regression of $H$ against $\triangle \mathrm{E}$ and annual $\mathrm{PAR}_{0}$ (all three variables logtransformed), yielding the following relationship:

$H=q \times \operatorname{PAR}_{0}^{0.46} \times \Delta e^{-0.21}$,

where $q$ is a fitted constant, which subsumes the proportionality between $\Delta E$ and $D$. This relationship suggests a further simplification of Eq. (A7) to allow for the compensating effect of reduced vegetation height on the costs of water 
transport in more arid climates. We made the approximation $H \propto \Delta E^{-0.25}$, leading to

$$
\frac{c_{\mathrm{i}}}{c_{\mathrm{a}}}=\frac{1}{1+C^{\prime} \times \sqrt{\frac{\eta}{K}} \times \Delta E^{0.25}},
$$

where $C^{\prime}=q C$. Temperature effects were imposed through the known temperature dependencies of $\eta$ and $K$ (Prentice et al., 2014). The variation of $K$ with elevation takes account of the effect of $p_{\mathrm{O}}$ (the partial pressure of $\left.\mathrm{O}_{2}\right)$ as $K=K_{\mathrm{c}}(1$ $+p_{\mathrm{O}} / K_{\mathrm{O}}$ ), where $K_{\mathrm{c}}$ and $K_{\mathrm{O}}$ are the Michaelis-Menten coefficients of Rubisco for carboxylation (in the absence of $\mathrm{O}_{2}$ ) and oxygenation, respectively. $p_{\mathrm{O}}$ declines with elevation in proportion to atmospheric pressure $(P)$, which we approximated by

$P=101.325 \times e^{-0.114 \times z}$

(Jacob, 1999). We estimated $C^{\prime}$ based on the common observation that $c_{\mathrm{i}} / c_{\mathrm{a}} \approx 0.8$ at low elevations in warm, mesic climates. As a reference case, we considered $z=0 \mathrm{~km}, \mathrm{mGDD}_{0}=18^{\circ} \mathrm{C}$ and $\Delta E=100 \mathrm{~mm}$ (similar to the environment of Sydney, Australia), yielding $C^{\prime}=$ $15.47 \mathrm{~mm}^{-0.25} \mathrm{~s}^{-0.5}$.

Although the optimal $c_{\mathrm{i}} / c_{\mathrm{a}}$ ratio is derived in pressure units (to account properly for elevation effects), $c_{\mathrm{i}}$ and $\Gamma^{*}$ are in mole fraction units $\left(\mu \mathrm{mol} \mathrm{mol}^{-1}\right)$ in the full model for GPP. This takes care of the fact that $\Gamma^{*}$ and the partial pressure of $\mathrm{CO}_{2}$ both decline in proportion to atmospheric pressure.

\section{A5 Photorespiratory compensation point $\left(\Gamma^{*}\right)$}

The photorespiratory compensation point $\left(\Gamma^{*}\right)$ depends strongly on temperature. Bernacchi et al. (2004) fitted an Arrhenius relationship to in vivo measurements of $\Gamma^{*}$ at different temperatures:

$\Gamma^{*}=e^{c-\frac{\Delta H}{R \times T},}$

where $c=19.02, \Delta H$ is the activation energy $(37.83 \mathrm{~kJ}$ $\left.\mathrm{mol}^{-1}\right), R$ is the molar gas constant $\left(8.314 \mathrm{~J} \mathrm{~mol}^{-1} \mathrm{~K}^{-1}\right)$ and $T$ is the temperature in $K$. We substituted growing-season mean temperature $\left(\mathrm{mGDD}_{0}\right)$ for $T$ to obtain an estimate of the effective $\Gamma^{*}$ during the growing season. 
Acknowledgements. HW was funded by the Australian Research Council through a Discovery Grant (to ICP and Ian Wright) "Nextgeneration vegetation model based on functional traits" (grant no. DP120103600), and TWD by Imperial College under a start-up grant to ICP. We thank Brad Evans, Trevor Keenan, Vincent Maire, Ning Dong and Ian Wright for discussions, and Brad Evans for helping with the flux partitioning. This paper is a contribution to the AXA Chair Programme on Biosphere and Climate Impacts and Imperial College's initiative on Grand Challenges in Ecosystems and the Environment. This work used free fair-use eddy covariance data acquired by the FLUXNET community and, in particular, by the following networks: AmeriFlux (US Department of Energy, Biological and Environmental Research, Terrestrial Carbon Program (DE-FG02-04ER63917 and DE-FG02-04ER63911)), AsiaFlux, CarboEuropeIP, Fluxnet-Canada (supported by CFCAS, NSERC, BIOCAP, Environment Canada, and NRCan), OzFlux and TCOS-Siberia. We acknowledge the financial support to the eddy covariance data harmonization provided by CarboEuropeIP, FAOGTOS-TCO, iLEAPS, Max Planck Institute for Biogeochemistry, National Science Foundation, University of Tuscia, Université Laval and Environment Canada and US Department of Energy and the database development and technical support from Berkeley Water Center, Lawrence Berkeley National Laboratory, Microsoft Research eScience, Oak Ridge National Laboratory, University of California-Berkeley, University of Virginia.

Edited by: R. Keeling

\section{References}

Ahlström, A., Schurgers, G., Arneth, A., and Smith, B.: Robustness and uncertainty in terrestrial ecosystem carbon response to CMIP5 climate change projections, Environ. Res. Lett., 7, 044008, doi:10.1088/1748-9326/7/4/044008, 2012.

Allen, R. G., Walter, I. A., Elliott, R. L., Howell T. A., Itenfisu D., Jensen, M. E., and Snyder, R. L.: The ASCE Standardized Reference Evapotranspiration Equation, Am. Soc. Civ. Engin., Reston, Virginia, 2005.

Anav, A., Friedlingstein, P., Kidston, M., Bopp, L., Ciais, P., Cox, P., Jones, C., Jung, M., Myneni, R., and Zhu, Z.: Evaluating the Land and Ocean Components of the Global Carbon Cycle in the CMIP5 Earth System Models, J. Clim., 26, 6801-6843, 2013.

Aoki, M., Fujii, K., and Kitayama, K.: Environmental control of root exudation of low-molecular weight organic acids in tropical rainforests, Ecosystems, 15, 1194-1203, 2012.

Arora, V. K., Boer, G. J., Friedlingstein, P., Eby, M., Jones, C. D., Christian, J. R., Bonan, G., Bopp, L., Brovkin, V., and Cadule, P.: Carbon-concentration and carbon-climate feedbacks in CMIP5 Earth system models, J. Clim., 26, 5289-5314, 2013.

Badawy, B., Rödenbeck, C., Reichstein, M., Carvalhais, N., and Heimann, M.: Technical Note: The Simple Diagnostic Photosynthesis and Respiration Model (SDPRM), Biogeosciences, 10, 6485-6508, doi:10.5194/bg-10-6485-2013, 2013.

Batjes, N. H.: Harmonized soil profile data for applications at global and continental scales: updates to the WISE datase, Soil Manage., 25, 124-127, 2009.

Beer, C., Reichstein, M., Tomelleri, E., Ciais, P., Jung, M., Carvalhais, N., Rödenbeck, C., Arain, M. A., Baldocchi, D., and Bonan,
G. B.: Terrestrial gross carbon dioxide uptake: global distribution and covariation with climate, Science, 329, 834-838, 2010.

Bernacchi, C. J., Pimentel, C., and Long, S. P.: In vivo temperature response functions of parameters required to model RuBPlimited photosynthesis, Plant, Cell Environ., 26, 1419-1430, 2003.

Bonan, G. B.: Physiological derivation of the observed relationship between net primary production and mean annual air temperature, Tellus B, 45, 397-408, 1993.

Cheng, Y. B., Zhang, Q., Lyapustin, A. I., Wang, Y., and Middleton, E. M.: Impacts of light use efficiency and fAPR parameterization on gross primary production modeling, Agr. Forest Meteorol., 189/190, 187-197, 2014.

Churkina, G. and Running, S. W.: Contrasting climatic controls on the estimated productivity of global terrestrial biomes, Ecosystems, 1, 206-215, 1998.

Ciais, P., Sabine, C., Govindasamy, B., Bopp, L., Brovkin, V., Canadell, J., Chhabra, A., DeFries, R., Galloway, J., Heimann, M., Jones, C., Le Queìreì, C., Myneni, R., Piao, S., and Thornton, P.: Chapter 6: Carbon and Other Biogeochemical Cycles, in: Climate Change 2013: The Physical Science Basis, edited by: Stocker, T., Qin, D., and Platner, G.-K., 465-570, 2013.

Collatz, G. J., Berry, J. A., and Clark, J. S.: Effects of climate and atmospheric $\mathrm{CO}_{2}$ partial pressure on the global distribution of $\mathrm{C}_{4}$ grasses: present, past, and future, Oecologia, 114, 441-454, 1998.

Cramer, W. and Prentice, I. C.: Simulation of regional soil moisture deficits on a European scale, Norsk Geografisk Tidsskrift Norwegian Journal of Geography, 42, 149-151, 1988.

Del Grosso, S., Parton, W., Stohlgren, T., Zheng, D., Bachelet, D., Prince, S., Hibbard, K., and Olson, R.: Global potential net primary production predicted from vegetation class, precipitation, and temperature, Ecology, 89, 2117-2126, 2008.

DeLucia, E., Drake, J. E., Thomas, R. B., and Gonzalez, M.: Forest carbon use efficiency: is respiration a constant fraction of gross primary production?, Glob. Change Biol., 13, 1157-1167, 2007.

Denman, K. L., Brasseur, G., Chidthaisong, A., Ciacis, P., Cox, P. M., Hauglustaine, D., Heinze, C., Holland, E., Jacob, D., Lohmann, U., Ramachandran, S., Da Silva Dias, P. L., Wofsy, S. C., and Zhang, X.: Couplings Between Changes in the Climate System and Biogeochemistry, in: Climate Change 2007: The Physical Science Basis. Contribution of Working Group I to the Fourth Assessment Report of the Intergovernmental Panel on Climate Change, edited by: Solomon, S., Qin, D., Manning, M., Chen, Z., Marquis, M., Averyt, K. B., Tignor, M., and Miller, H. L., Cambridge University Press, Cambridge, United Kingdom and New York, NY, USA, 500-587, 2007.

Donohue, R. J., Roderick, M. L., McVicar, T. R., and Farquhar, G. D.: Impact of $\mathrm{CO}_{2}$ fertilization on maximum foliage cover across the globe's warm, arid environments, Geophys. Res. Lett., 40, 3031-3035, 2013.

Farquhar, G., von Caemmerer, S., and Berry, J.: A biochemical model of photosynthetic $\mathrm{CO}_{2}$ assimilation in leaves of $\mathrm{C}_{3}$ species, Planta, 149, 78-90, 1980.

Fatichi, S., Leuzinger, S., and Körner, C.: Moving beyond photosynthesis: from carbon source to sink vegetation modeling, New Phytol., 201, 1086-1095, 2013.

Fernández-Martínez, M., Vicca, S., Janssens, I. A., Sardans, J., Luyssaert, S., Campioli, M., Chapin, F. S. III, Ciais, P., Malhi, 
Y., Obersteiner, M., Papale, D., Piao, S. L., Reichstein, M., Rodà, F., and Peñuelas, J.: Nutrient availability as the key regulator of global forest carbon balance, Nat. Clim. Change, 4, 471-476, 2014.

Field, C. B., Randerson, J. T., and Malmström, C. M.: Global net primary production: combining ecology and remote sensing, Remote Sens. Environ., 51, 74-88, 1995.

Friedlingstein, P., Cox, P., Betts, R., Bopp, L., Von Bloh, W., Brovkin, V., Cadule, P., Doney, S., Eby, M., and Fung, I.: Climate-carbon cycle feedback analysis: Results from the $\mathrm{C}^{4}$ MIP model intercomparison, J. Clim., 19, 3337-3353, 2006.

Friedlingstein, P., Meinshausen, M., Arora, V. K., Jones, C. D., Anav, A., Liddicoat, S. K., and Knutti, R.: Uncertainties in CMIP5 climate projections due to carbon cycle feedbacks, J. Clim., 27, 511-526, 2014.

Friend, A., Woodward, F., and Switsur, V.: Field measurements of photosynthesis, stomatal conductance, leaf nitrogen and $\delta^{13} \mathrm{C}$ along altitudinal gradients in Scotland, Funct. Ecol., 3, 117-122, 1989.

Gallego-Sala, A., Clark, J., House, J., Orr, H., Prentice, I. C., Smith, P., Farewell, T., and Chapman, S.: Bioclimatic envelope model of climate change impacts on blanket peatland distribution in Great Britain, Clim. Res., 45, 151-162, 2010.

Garbulsky, M. F., Peñuelas, J., Papale, D., Ardö, J., Goulden, M. L., Kiely, G., Richardson, A. D., Rotenberg, E., Veenendaal, E. M., and Filella, I.: Patterns and controls of the variability of radiation use efficiency and primary productivity across terrestrial ecosystems, Glob. Ecol. Biogeogr., 19, 253-267, 2010.

Gobron, N., Pinty, B., Aussedat, O., Chen, J. M., Cohen, W. B., Fensholt, R., Gond, V., Huemmrich, K. F., Lavergne, T., Melin, F., Privette, J. L., Sandholt, I., Taberner, M., Turner, D. P., Verstraete, M. M., and Widlowski, J.-L.: Evaluation of fraction of absorbed photosynthetically active radiation products for different canopy radiation transfer regimes: Methodology and results using Joint Research Center products derived from SeaWiFS against ground-based estimations, J. Geophys. Res.Atmospheres, 111, D13110, doi:10.1029/2005JD006511, 2006.

Haxeltine, A. and Prentice, I. C.: BIOME3: An equilibrium terrestrial biosphere model based on ecophysiological constraints, resource availability, and competition among plant functional types, Global Biogeochem. Cy., 10, 693-709, 1996.

Hickler, T., Smith, B., Prentice, I. C., Mjöfors, K., Miller, P., Arneth, A., and Sykes, M. T.: $\mathrm{CO}_{2}$ fertilization in temperate FACE experiments not representative of boreal and tropical forests, Glob. Change Biol., 14, 1531-1542, 2008.

Hoffman, F. M., Randerson, J. T., Arora, V. K., Bao, Q., Six, K. D., Cadule, P., Ji, D., Jones, C. D., Kawamiya, M., and Khatiwala, S.: Causes and implications of persistent atmospheric carbon dioxide biases in Earth system models, J. Geophys. Res., 119, 141$162,2014$.

Horn, J. E. and Schulz, K.: Identification of a general light use efficiency model for gross primary production, Biogeosciences, 8 , 999-1021, doi:10.5194/bg-8-999-2011, 2011.

Huston, M. A. and Wolverton, S.: The global distribution of net primary production: resolving the paradox, Ecol. Monogr., 79, 343-377, 2009.

Jacob, D.: Introduction to Atmospheric Chemistry, Princeton University Press, 1999.
Jones, C., Robertson, E., Arora, V., Friedlingstein, P., Shevliakova, E., Bopp, L., Brovkin, V., Hajima, T., Kato, E., and Kawamiya, M.: 21st century compatible $\mathrm{CO}_{2}$ emissions and airborne fraction simulated by CMIP5 Earth System models under 4 representative concentration pathways, J. Clim., 26, 4398-4413, 2013.

Keenan, T. F., Gray, J., Friedl, M. A., Toomey, M., Bohrer, G., Hollinger, D. Y., Munger, J. W., O'Keefe, J., Schmid, H. P., Wing, I. S., Yang, B., and Richardson, A. D.: Net carbon uptake has increased through warming-induced changes in temperate forest phenology, Nat. Clim. Change, 4, 598-604, 2014.

Kelley, D. I., Prentice, I. C., Harrison, S. P., Wang, H., Simard, M., Fisher, J. B., and Willis, K. O.: A comprehensive benchmarking system for evaluating global vegetation models, Biogeosciences, 10, 3313-3340, doi:10.5194/bg-10-3313-2013, 2013.

Kerkhoff, A. J., Enquist, B. J., Elser, J. J., and Fagan, W. F.: Plant allometry, stoichiometry and the temperature-dependence of primary productivity, Global Ecol. Biogeogr., 14, 585-598, 2005.

Knorr, W. and Heimann, M.: Impact of drought stress and other factors on seasonal land biosphere $\mathrm{CO}_{2}$ exchange studied through an atmospheric tracer transport model, Tellus B, 47, 471-489, 1995.

Körner, C. and Diemer, M.: In situ photosynthetic responses to light, temperature and carbon dioxide in herbaceous plamts from low and high altitude, Funct. Ecol., 1, 179-194, 1987.

Kutzbach, J. and Gallimore, R.: Sensitivity of a coupled atmosphere/mixed layer ocean model to changes in orbital forcing at 9000 years BP, J. Geophys. Res., 93, 803-821, 1988.

Lee, T., Barrott, S., and Reich, P.: Photosynthetic responses of 13 grassland species across 11 years of free-air $\mathrm{CO} 2$ enrichment is modest, consistent and independent of N supply, Glob. Change Biol., 17, 2893-2904, 2011.

Linacre, E.: Estimating the net-radiation flux, Agr. Meteorol., 5, 4963, 1968.

Long, S., Postl, W., and Bolhar-Nordenkampf, H.: Quantum yields for uptake of carbon dioxide in $\mathrm{C}_{3}$ vascular plants of contrasting habitats and taxonomic groupings, Planta, 189, 226-234, 1993.

Los, S. O.: Analysis of trends in fused AVHRR and MODIS NDVI data for 1982-2006: Indication for a $\mathrm{CO}_{2}$ fertilization effect in global vegetation, Global Biogeochem. Cy., 276, 318-330, 2013.

Luyssaert, S., Inglima, I., Jung, M., Richardson, A. D., Reichstein, M., Papale, D., Piao, S. L., Schulze, E. D., Wingate, L., Matteucci, G., Aragao, L., Aubinet, M., Beer, C., Bernhofer, C., Black, K. G., Bonal, D., Bonnefond, J. M., Chambers, J., Ciais, P., Cook, B., Davis, K. J., Dolman, A. J., Gielen, B., Goulden, M., Grace, J., Granier, A., Grelle, A., Griffis, T., GrüNwald, T., Guidolotti, G., Hanson, P. J., Harding, R., Hollinger, D. Y., Hutyra, L. R., Kolari, P., Kruijt, B., Kutsch, W., Lagergren, F., Laurila, T., Law, B. E., Le Maire, G., Lindroth, A., Loustau, D., Malhi, Y., Mateus, J., Migliavacca, M., Misson, L., Montagnani, L., Moncrieff, J., Moors, E., Munger, J. W., Nikinmaa, E., Ollinger, S. V., Pita, G., Rebmann, C., Roupsard, O., Saigusa, N., Sanz, M. J., Seufert, G., Sierra, C., Smith, M. L., Tang, J., Valentini, R., Vesala, T., and Janssens, I. A.: $\mathrm{CO}_{2}$ balance of boreal, temperate, and tropical forests derived from a global database, Glob. Change Biol., 13, 2509-2537, 2007.

Maire, V., Martre, P., Kattge, J., Gastal, F., Esser, G., Fontaine, S., and Soussana, J.-F.: The coordination of leaf photosynthesis links $\mathrm{C}$ and $\mathrm{N}$ fluxes in $\mathrm{C}_{3}$ plant species, PloS one, 7, e38345, doi:10.1371/journal.pone.0038345, 2012. 
McCallum, I., Wagner, W., Schmullius, C., Shvidenko, A., Obersteiner, M., Fritz, S., and Nilsson, S.: Satellite-based terrestrial production efficiency modeling, Carb. Balance Manage., 4, doi:10.1186/1750-0680-4-8, 2009.

McCallum, I., Wagner, W., Schmullius, C., Shvidenko, A., Obersteiner, M., Fritz, S., and Nilsson, S.: Comparison of four global FAPAR datasets over Northern Eurasia for the year 2000, Remote Sens. Environ., 114, 941-949, 2010.

McCallum, I., Franklin, O., Moltchanova, E., Merbold, L., Schmullius, C., Shvidenko, A., Schepaschenko, D., and Fritz, S.: Improved light and temperature responses for light-useefficiency-based GPP models, Biogeosciences, 10, 6577-6590, doi:10.5194/bg-10-6577-2013, 2013.

Mercado, L. M., Bellouin, N., Sitch, S., Boucher, O., Huntingford, C., Wild, M., and Cox, P. M.: Impact of changes in diffuse radiation on the global land carbon sink, Nature, 458, 1014-1017, 2009.

Monteith, J. L. and Moss, C. J.: Climate and the efficiency of crop production in Britain [and Discussion], Philosoph. Transact. Roy. Soc. London B, 281, 277-294, 1977.

Norby, R. J., DeLucia, E. H., Gielen, B., Calfapietra, C., Giardina, C. P., King, J. S., Ledford, J., McCarthy, H. R., Moore, D. J., and Ceulemans, R.: Forest response to elevated $\mathrm{CO}_{2}$ is conserved across a broad range of productivity, Proc. Natl. Acad. Sci. USA, 102, 18052-18056, 2005.

Norby, R. J., Warren, J. M., Iversen, C. M., Medlyn, B. E., and McMurtrie, R. E.: $\mathrm{CO}_{2}$ enhancement of forest productivity constrained by limited nitrogen availability, Proc. Natl. Acad. Sci., 107, 19368-19373, 2010.

Pickett-Heaps, C. A., Canadell, J. G., Briggs, P. R., Gobron, N., Haverd, V., Paget, M. J., Pinty, B., and Raupach, M. R.: Evaluation of six satellite-derived Fraction of Absorbed Photosynthetic Active Radiation (FAPAR) products across the Australian continent, Remote Sens. Environ., 140, 241-256, 2014.

Pongratz, J., Lobell, D., Cao, L., and Caldeira, K.: Crop yields in a geoengineered climate, Nat. Clim. Change, 2, 101-105, 2012.

Poorter, H., Niklas, K. J., Reich, P. B., Oleksyn, J., Poot, P., and Mommer, L.: Biomass allocation to leaves, stems and roots: meta-analyses of interspecific variation and environmental control, New Phytologist, 193, 30-50, 2012.

Potter, C. S., Randerson, J. T., Field, C. B., Matson, P. A., Vitousek, P. M., Mooney, H. A., and Klooster, S. A.: Terrestrial ecosystem production: a process model based on global satellite and surface data, Global Biogeochem. Cy., 7, 811-841, 1993.

Prentice, I. C., Dong, N., Gleason, S. M., Maire, V., and Wright, I. J.: Balancing the costs of carbon gain and water transport: testing a new theoretical framework for plant functional ecology, Ecol. lett., 17, 82-91, 2014.

Ruimy, A., Jarvis, P. G., Baldocchi, D. D., and Saugier, B: $\mathrm{CO}_{2}$ fluxes over plant canopies and solar radiation: a review, Adv. Ecol. Res., 26, 1-68, 1995.

Running, S. W., Nemani, R. R., Heinsch, F. A., Zhao, M., Reeves, M., and Hashimoto, H.: A continuous satellite-derived measure of global terrestrial primary production, Bioscience, 54, 547560, 2004

Simard, M., Pinto, N., Fisher, J. B., and Baccini, A.: Mapping forest canopy height globally with spaceborne lidar, Journal of Geophys. Res., 116, G04021, doi:10.1029/2002GL016038, 2011.
Sitch, S., Smith, B., Prentice, I. C., Arneth, A., Bondeau, A., Cramer, W., Kaplan, J. O., Levis, S., Lucht, W., Sykes, M. T., Thonicke, K., and Venevsky, S.: Evaluation of ecosystem dynamics, plant geography and terrestrial carbon cycling in the LPJ dynamic global vegetation model, Glob. Change Biol., 9, 161-185, 2003.

Sitch, S., Huntingford, C., Gedney, N., Levy, P., Lomas, M., Piao, S., Betts, R., Ciais, P., Cox, P., and Friedlingstein, P.: Evaluation of the terrestrial carbon cycle, future plant geography and climate-carbon cycle feedbacks using five Dynamic Global Vegetation Models (DGVMs), Glob. Change Biol., 14, 2015-2039, 2008.

Sykes, M. T., Prentice, I. C., and Cramer, W.: A bioclimatic model for the potential distributions of north European tree species under present and future climates, J. Biogeogr., 23, 203-233, 1996.

Thomas, R. Q., Zaehle, S., Templer, P. H., and Goodale, C. L.: Global patterns of nitrogen limitation: confronting two global biogeochemical models with observations, Glob. Change Biol., 19, 2986-2998, 2013.

Todd-Brown, K. E. O., Randerson, J. T., Post, W. M., Hoffman, F. M., Tarnocai, C., Schuur, E. A. G., and Allison, S. D.: Causes of variation in soil carbon simulations from CMIP5 Earth system models and comparison with observations, Biogeosciences, 10, 1717-1736, doi:10.5194/bg-10-1717-2013, 2013.

Ukkola, A. and Prentice, I. C.: A worldwide analysis of trends in water-balance evapotranspiration, Hydrol. Earth Syst. Sci., 17, 4177-4187, 2013, http://www.hydrol-earth-syst-sci.net/17/4177/2013/.

Verma, M., Friedl, M. A., Richardson, A. D., Kiely, G., Cescatti, A., Law, B. E., Wohlfahrt, G., Gielen, B., Roupsard, O., Moors, E. J., Toscano, P., Vaccari, F. P., Gianelle, D., Bohrer, G., Varlagin, A., Buchmann, N., van Gorsel, E., Montagnani, L., and Propastin, P.: Remote sensing of annual terrestrial gross primary productivity from MODIS: an assessment using the FLUXNET La Thuile data set, Biogeosciences, 11, 2185-2200, doi:10.5194/bg11-2185-2014, 2014.

Vicca, S., Luyssaert, S., Peñuelas, J., Campioli, M., Chapin, F. S. III, Ciais, P., Heinemeyer, A., Högberg, P., Kutsch, W. L., Law, B. E., Malhi, Y., Papale, D., Piao, S. L., Reichstein, M., Schulze, E. D., and janssens, I. A.: Fertile forests produce biomass more efficiently, Ecol. Lett., 15, 520-526, 2012.

Wang, H., Prentice, I. C., and Ni, J.: Primary production in forests and grasslands of China: contrasting environmental responses of light- and water-use efficiency models, Biogeosciences, 9, 46894705, doi:10.5194/bg-9-4689-2012, 2012.

Waring, R., Landsberg, J., and Williams, M.: Net primary production of forests: a constant fraction of gross primary production?, Tree Physiology, 18, 129-134, 1998.

Weedon, G. P., Gomes, S., Balsamo, G., Best, M. J., Bellouin, N., and Viterbo, P.: WATCH forcing databased on ERA-INTERIM. Retrieved July 24, 2012.

Welp, L. R., Keeling, R. F., Meijer, H. A., Bollenbacher, A. F., Piper, S. C., Yoshimura, K., Francey, R. J., Allison, C. E., and Wahlen, M.: Interannual variability in the oxygen isotopes of atmospheric $\mathrm{CO}_{2}$ driven by El Niño, Nature, 477, 579-582, 2011.

Willson, R. C. and Mordvinov, A. V.: Secular total solar irradiance trend during solar cycles 21-23, Geophys. Res. Lett., 30, 1199, doi:10.1029/2011JG001708, 2003. 
Wright, I. J., Reich, P. B., and Westoby, M.: Least-cost input mixtures of water and nitrogen for photosynthesis, The American Naturalist, 161, 98-111, 2003.

Yuan, W., Liu, S., Zhou, G., Zhou, G., Tieszen, L. L., Baldocchi, D., Bernhofer, C., Gholz, H., Goldstein, A. H., Goulden, M. L., Hollinger, D. Y., Hu, Y., Law, B. E., Stoy, P. C., Vesala, T., and Wofsy, S. C.: Deriving a light use efficiency model from eddy covariance flux data for predicting daily gross primary production across biomes, Agr. For. Meteorol., 143, 189-207, 2007.
Yuan, W., Liu, S., Cai, W., Dong, W., Chen, J., Arain, A., Blanken, P. D., Cescatti, A., Wohlfahrt, G., Georgiadis, T., Genesio, L., Gianelle, D., Grelle, A., Kiely, G., Knohl, A., Liu, D., Marek, M., Merbold, L., Montagnani, L., Panferov, O., Peltoniemi, M., Rambal, S., Raschi, A., Varlagin, A., and Xia, J.: Are vegetationspecific model parameters required for estimating gross primary production?, Geosci. Model Dev. Discuss., 6, 5475-5488, doi:10.5194/gmdd-6-5475-2013, 2013.

Zaehle, S. and Dalmonech, D.: Carbon-nitrogen interactions on land at global scales: current understanding in modelling climate biosphere feedbacks, Curr. Opin. Environ. Sustainab., 3, 311$320,2011$. 